\title{
Um Novo Fôlego para a Acta Médica Portuguesa
}

\section{Fresh Wind at Acta Médica Portuguesa}

Tiago VILLANUEVA $\triangle^{1,2}$

Acta Med Port 2017 Oct;30(10):667-668 - https://doi.org/10.20344/amp.9854

Palavras-chave: Edição; Políticas Editoriais; Portugal; Publicações Periódicas como Assunto

Keywords: Editorial Policies; Periodicals as Topic; Portugal; Publishing

É uma honra suceder ao Professor Rui Tato Marinho e ao Professor José Manuel Silva como novo editor-chefe da Acta Médica Portuguesa.

A Acta Médica Portuguesa (AMP) é o equivalente em Portugal da revista BMJ (Reino Unido) ou da JAMA (Estados Unidos da América) por ser a revista científica de âmbito generalista da respetiva associação médica nacional. Apesar de a AMP se encontrar num patamar muito diferente das publicações supra-citadas, tem objetivos comuns, nomeadamente ser uma referência, ajudar os médicos a tomar melhores decisões na sua prática clínica diária e influenciar os decisores na área da saúde.

Esta tarefa de aproximar a AMP desses patamares de excelência não é fácil de desempenhar. Uma das queixas principais dos autores que submetem artigos à AMP são os elevados tempos de decisão, havendo registos de artigos que permanecem no sistema durante vários meses sem que tenha sido tomada qualquer decisão editorial. Ainda que possam demorar vários meses desde a submissão até que finalmente sejam aceites, com provavelmente várias rondas de revisão pelo meio, os artigos que não se adequam ao âmbito da AMP devem ser rejeitados rapidamente de forma a permitir que o autor envie com celeridade o seu trabalho para outras publicações. É o que acontece nas grandes revistas médicas generalistas, que dispõem de uma equipa editorial numerosa, é o que não tem sido sempre possível acontecer na AMP devido às lacunas em recursos humanos, quer a nível da equipa técnica fixa, quer a nível da equipa editorial. Esta demora será, a partir de agora, muito menos provável, não só porque me encontro com horário reduzido no Serviço Nacional de Saúde - de forma a poder dispor de tempo protegido para me dedicar e acompanhar a actividade diária da AMP num regime de semi-profissionalização (já há muito tempo considerado necessário ${ }^{1}$ ) - como também alimentamos esperanças de poder expandir a equipa, passando a contar com mais um elemento técnico, dois editores-chefes adjuntos e uma série de Editores Associados.

Por outro lado, gostava também de encorajar os leitores a registarem-se como revisores na plataforma da AMP (www.actamedicaportuguesa.com). Existem actualmente cerca de 3500 revisores registados na nossa plataforma, mas é importante que este número aumente consideravelmente, de forma a permitir que os artigos sejam revistos mais rapidamente. Com efeito, parte dos atrasos decorre da dificuldade em encontrar avaliadores, sobretudo em áreas muito especializadas em que o pool de revisores disponíveis é muito limitado.

Um dos aspetos que me surpreendeu quando assumi este cargo foi o número de artigos submetidos em Inglês. Continuaremos a encorajar esta prática, já que a publicação de artigos na língua de Shakespeare reverte a favor dos autores e da AMP, potenciando o alcance e impacto do artigo bem como a probabilidade de que o trabalho seja citado (o que se refletirá no fator de impacto da revista). Contudo, tenho notado que alguns artigos têm sido aceites sem que os autores tenham feito uma revisão cuidada ao nível do inglês escrito. A partir de agora iremos passar a exigir aos autores de artigos redigidos em Inglês que os façam rever por um indivíduo nativo de língua inglesa ou por serviços profissionais de language polishing. Posso-vos assegurar que estes esforços não serão em vão, pois resultarão numa AMP mais preparada para disputar um lugar honroso no mercado global altamente competitivo em que se integra. Prova disso é termos leitores e autores de todo o mundo que nos remetem artigos. Tive oportunidade de constatar que países como os Estados Unidos, China ou a Austrália constam do nosso top-10 de países com mais visitas ao site. Além, naturalmente, de Portugal, recebemos com regularidade artigos provenientes de países da América Latina e esporadicamente de muitos outros países também.

Como devem imaginar, a grande prioridade da AMP neste momento é promover o aumento do seu fator de impacto, que é um dos grandes critérios em que os autores se baseiam para decidir onde submeter os seus artigos. Estamos confiantes que, com o desenvolvimento de um plano estratégico, será possível continuar a fazer subir este indicador, como aliás tem vindo a acontecer até hoje, o que permitirá atrair cada vez mais trabalhos de maior qualidade. No entanto, o trabalho estratégico que empreendemos hoje em prol da subida do fator de impacto só virá a produzir

\footnotetext{
1. Editor-Chefe. Acta Médica Portuguesa. Lisboa. Portugal.

2. Editor-Associado. The BMJ. Londres. Reino Unido.

$\triangle$ Autor correspondente: Tiago Villanueva. tiago.villanueva@ordemdosmedicos.pt

Recebido: 24 de outubro de 2017 - Aceite: 24 de outubro de 2017| Copyright @ Ordem dos Médicos 2017
} 
resultados, no mínimo, daqui a dois ou três anos, pelo que a principal medida estratégica a implementar a curto prazo será rever as normas editoriais e robustecer os processos editoriais. Por exemplo, a partir de agora passaremos a exigir o preenchimento e envio das reporting guidelines (e.g. STROBE, PRISMA, etc.) no momento da submissão do artigo, e só aceitaremos artigos reportando ensaios clínicos que tenham sido registados prospetivamente. ${ }^{2}$ Em relação aos processos editoriais, além de querermos tornar mais célere a revisão por pares, pretendemos também assegurar que todos os artigos reportando estudos de investigação sejam revistos não só por peritos na matéria em causa, mas igualmente por um estatístico ou perito em metodologia de investigação. Por outro lado, e mal esteja constituída a equipa de editores, passaremos a realizar reuniões editoriais regulares, onde os artigos com revisões favoráveis serão sujeitos a escrutínio mais profundo e discutidos em grupo, o que permitirá que as decisões finais sejam tomadas de forma mais ponderada e informada.

A nível de conteúdos, temos algumas novidades. Queremos começar a publicar também protocolos de investigação e encorajamos desde já o envio de artigos que abordem questões de metodologia de investigação e de estatística

\section{REFERÊNCIAS}

1. Marinho RT, Donato H, Fernandez-Llimos F, Massano J, Silva JM, Almeida M, et al. Think tank: strategic report on the scientific biomedical publication in Portugal. Acta Med Port. 2014;27:1-3.

2. Fredrickson MJ, Ilfeld BM. Prospective trial registration for clinical médica, que se dirijam e sejam sobretudo úteis a jovens médicos-investigadores em início de carreira, à semelhança dos artigos da secção "Research Methods and Reporting" da revista BMJ. ${ }^{3}$ Não hesitem em verificar com antecedência se os vossos trabalhos são adequados à AMP: enviem-nos todas as questões que tenham sobre artigos que já escreveram, estão a escrever, ou em concepção ainda para o email secretariado@actamedicaportuguesa. com. Encorajo sempre potenciais autores a esclarecerem as suas dúvidas junto da editorial previamente à submissão, para aferir das possibilidades realistas de um artigo ser ou não aceite para publicação, já que isso pode poupar imenso trabalho e tempo a todas as partes. De notar que mesmo nos casos em que encorajamos a submissão nunca é possível fazer promessas em relação à publicação.

Este ano esperamos pela primeira vez ultrapassar o marco sem precedentes de 1000 submissões. AActa Médica Portuguesa está viva, e recomenda-se.

\section{CONFLITOS DE INTERESSE}

O autor é editor-associado das revistas The BMJ e BMJ Open.

research: what is it, what is it good for, and why do I care? Reg Anesth Pain Med. 2011;36:619-24.

3. Groves T. Research methods and reporting. BMJ. 2008;337. 